\title{
Cyclodextrin-Driven Movement of Cucurbit[7]uril
}

\author{
Yu Liu*, Xiao-Yun Li, Heng-Yi Zhang, Chun-Ju Li, Fei Ding \\ Department of Chemistry, State Key Laboratory of Elemento-Organic Chemistry, Nankai \\ University, Tianjin 300071, P. R. China
}

\section{Contents in the Supporting Information}

Synthesis of $\mathrm{MVO}^{2+}$

Page S2

Figure S1 ${ }^{1} \mathrm{H}$ NMR spectra $\left(300 \mathrm{MHz}, \mathrm{D}_{2} \mathrm{O}, 298 \mathrm{~K}\right)$ of $\mathrm{MVO}^{2+}$

Page S2

Synthesis of $\mathrm{OV}^{2+}$

Page S3

Figure S2 ${ }^{1} \mathrm{H}$ NMR spectra $\left(300 \mathrm{MHz}, \mathrm{D}_{2} \mathrm{O}, 298 \mathrm{~K}\right)$ of $\mathrm{OV}^{2+}$

Page S3

Figure S3 ESI-MS of a solution containing $\mathrm{MVO}^{2+}$ and $\mathrm{CB}[7]$

Page S4

Figure S4 ${ }^{1} \mathrm{H}$ NMR spectra of $(\mathrm{A}) \mathrm{OV}^{2+}+2.4$ equiv. $\mathrm{CB}[7],(\mathrm{B}) \mathrm{OV}^{2+}+$ Page S5

2.4 equiv. $\mathrm{CB}[7]+4.0$ equiv. $\alpha-\mathrm{CD}$, (D) $\mathrm{OV}^{2+}+2.4$ equiv. $\mathrm{CB}[7]+8.0$ equiv. $\alpha-\mathrm{CD}$.

Figure S5 ESI-MS of a solution containing $\mathrm{OV}^{2+}$ and $\mathrm{CB}$ [7] in water

Page S6

Figure S6 ESI-MS of a solution containing $\mathrm{OV}^{2+}, \mathrm{CB}[7]$ and $\alpha-\mathrm{CD}$

Page S7

Figure S7

${ }^{1} \mathrm{H}$ NMR spectra of (A) $\mathrm{BV}^{2+}$, (B) $\mathrm{BV}^{2+}+1.0$ equiv. $\mathrm{CB}[7]$,

Page S8

(C) $\mathrm{BV}^{2+}+1.0$ equiv. $\mathrm{CB}[7]+10.0$ equiv. $\alpha-\mathrm{CD}$ and (D) $\mathrm{BV}^{2+}+10.0$ equiv. $\alpha-\mathrm{CD}$.

Figure S8 $\quad{ }^{1} \mathrm{H}$ NMR spectra of (A) $\mathrm{BnV}^{2+}$, (B) $\mathrm{BnV}^{2+}+1.0$ equiv. $\mathrm{CB}$ [7],

Page S9

(C) $\mathrm{BnV}^{2+}+1.0$ equiv. $\mathrm{CB}[7]+10.0$ equiv. $\alpha-\mathrm{CD}$ and (D) $\mathrm{BnV}^{2+}+10.0$ equiv. $\alpha-\mathrm{CD}$.

Figure S9 $\quad{ }^{1} \mathrm{H}$ NMR spectra of (A) $\mathrm{MV}^{2+}$, (B) $\mathrm{MV}^{2+}+1.0$ equiv. $\mathrm{CB}[7]$ Page S10 and $(\mathrm{C}) \mathrm{MV}^{2+}+10.0$ equiv. $\alpha-\mathrm{CD}$.

Figure S10 UV-Vis spectra of $[\mathrm{OV} \cdot \mathrm{CB}[7]]^{2+}$ in the presence of increasing

Page S11 concentrations of $\alpha-C D$

Figure S11 Partial ${ }^{1} \mathrm{H}$ ROESY spectra of a mixture of $\mathrm{MVO}^{2+}, \mathrm{CB}[7]$ and

Page S12 $\alpha-\mathrm{CD}$

Figure S12 Computer simulation of ITC titration curve using the "1:2 sequential binding sites" model in the case of complexation of $\alpha-\mathrm{CD}$ toward $[\mathrm{OV} \cdot \mathrm{CB}[7]]^{2+}$ 
Synthesis of MVO·BrI. A mixture of 4,4'-bipyridine (3.0 mmol) and $\mathrm{CH}_{3} \mathrm{I}(1.0 \mathrm{mmol})$ in $\mathrm{CHCl}_{3}$ was refluxed for 12 hours. The resulting precipitate was added to the solution of 1-Bromooctane $(5.0 \mathrm{mmol})$ in $\mathrm{CH}_{3} \mathrm{CN}$, and then the mixture was refluxed for 24 hours. The resulting precipitate was filtered, washed with $\mathrm{CH}_{3} \mathrm{CN}$, and then dried under vacuum. ${ }^{1} \mathrm{H}$ NMR of MVO·BrI (300MHz, $\left.\mathrm{D}_{2} \mathrm{O}\right), \delta 8.98(\mathrm{~d}, 2 \mathrm{H}), 8.92(\mathrm{~d}$, 2H), $8.40(\mathrm{t}, 4 \mathrm{H}), 4.59(\mathrm{t}, 2 \mathrm{H}), 4,37(\mathrm{~s}, 3 \mathrm{H}), 1.95(\mathrm{~m}, 2 \mathrm{H}), 1.23-1.12(\mathrm{~m}, 10 \mathrm{H}), 0.71(\mathrm{t}$, 3H). Anal. Calcd for $\mathrm{C}_{19} \mathrm{H}_{28} \mathrm{~N}_{2} \mathrm{BrI}$ : C 46.45, H 5.75, N 5.70; Found: C 46.52, H 5.87, N 5.46.

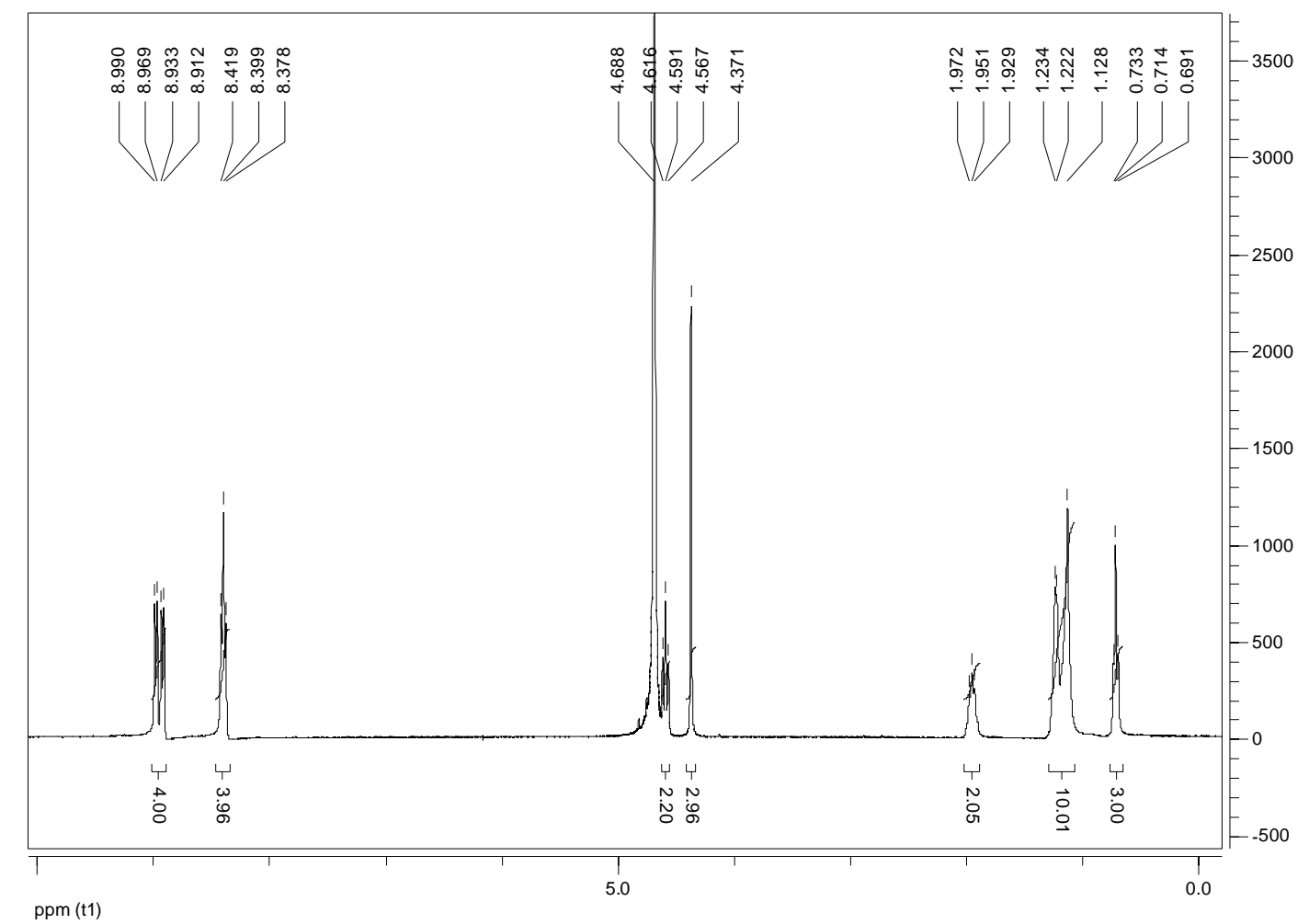

Figure S1. ${ }^{1} \mathrm{H}$ NMR spectra $\left(300 \mathrm{MHz}, \mathrm{D}_{2} \mathrm{O}, 298 \mathrm{~K}\right)$ of $\mathrm{MVO}^{2+}$. 
Synthesis of $\mathbf{O V} \cdot \mathbf{B r}_{2}$. A mixture of 4,4'-bipyridine $(1.0 \mathrm{mmol})$ and 1-bromooctane (6.0 mmol) in $\mathrm{CH}_{3} \mathrm{CN}$ was refluxed for 24 hours. The resulting precipitate was filtered, washed with $\mathrm{CH}_{3} \mathrm{CN}$, and then dried under vacuum. ${ }^{1} \mathrm{H}$ NMR of $\mathbf{O V} \cdot \mathrm{Br}_{2}(300 \mathrm{MHz}$, $\left.\mathrm{D}_{2} \mathrm{O}\right), \delta 8.94(\mathrm{~d}, 4 \mathrm{H}), 8.37(\mathrm{~d}, 4 \mathrm{H}), 4.56(\mathrm{t}, 4 \mathrm{H}), 1.91(\mathrm{~m}, 4 \mathrm{H}), 1.19-1.06(\mathrm{~m}, 20 \mathrm{H})$, $0.66(t, 6 \mathrm{H})$. Anal. Calcd for $\mathrm{C}_{26} \mathrm{H}_{42} \mathrm{~N}_{2} \mathrm{Br}_{2}$ : C 57.57, H 7.80, N 5.16; Found: C 57.50, H 7.62, N 5.36.

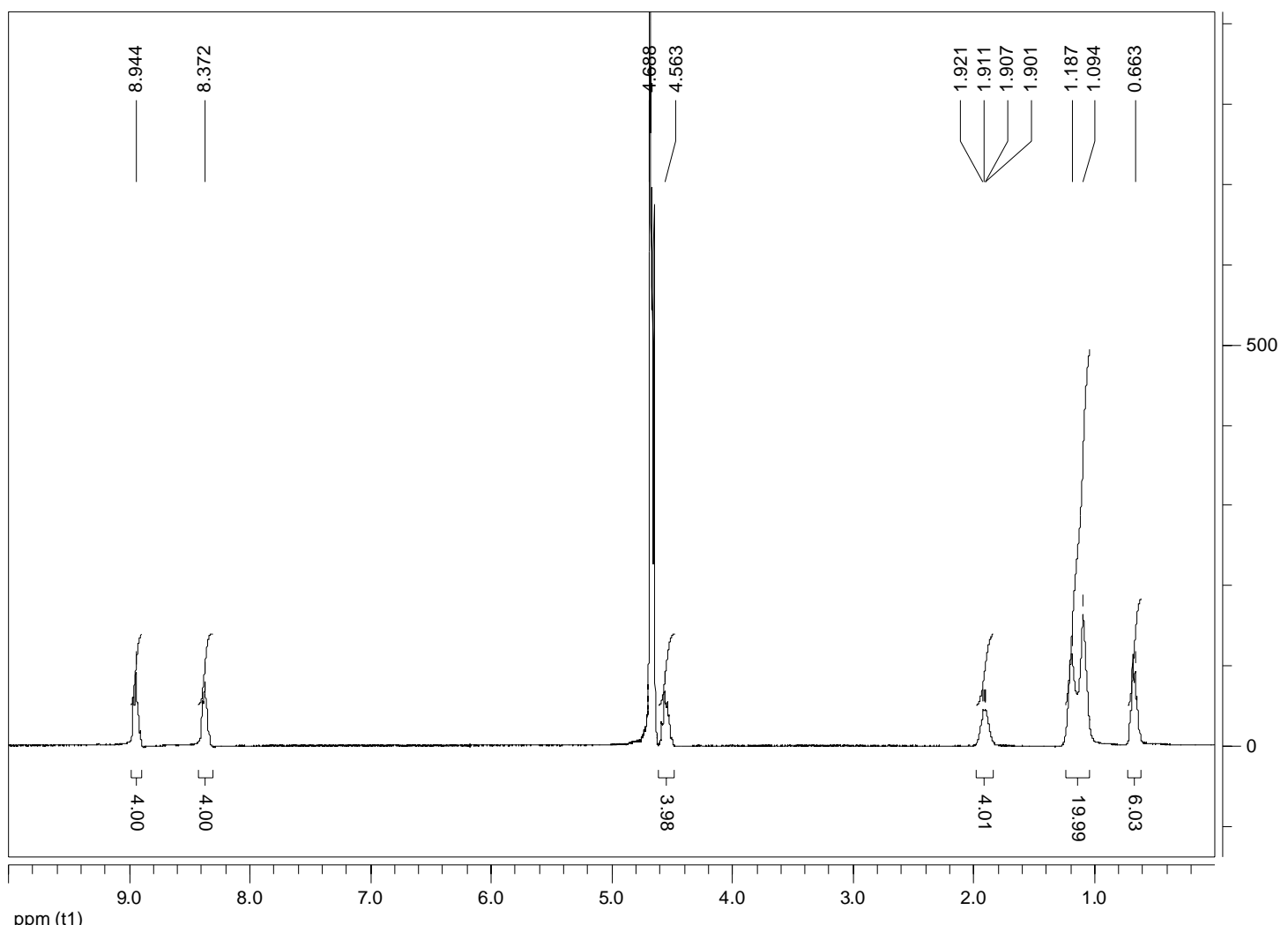

Figure S2. ${ }^{1} \mathrm{H}$ NMR spectra $\left(300 \mathrm{MHz}, \mathrm{D}_{2} \mathrm{O}, 298 \mathrm{~K}\right)$ of $\mathrm{OV}^{2+}$ 


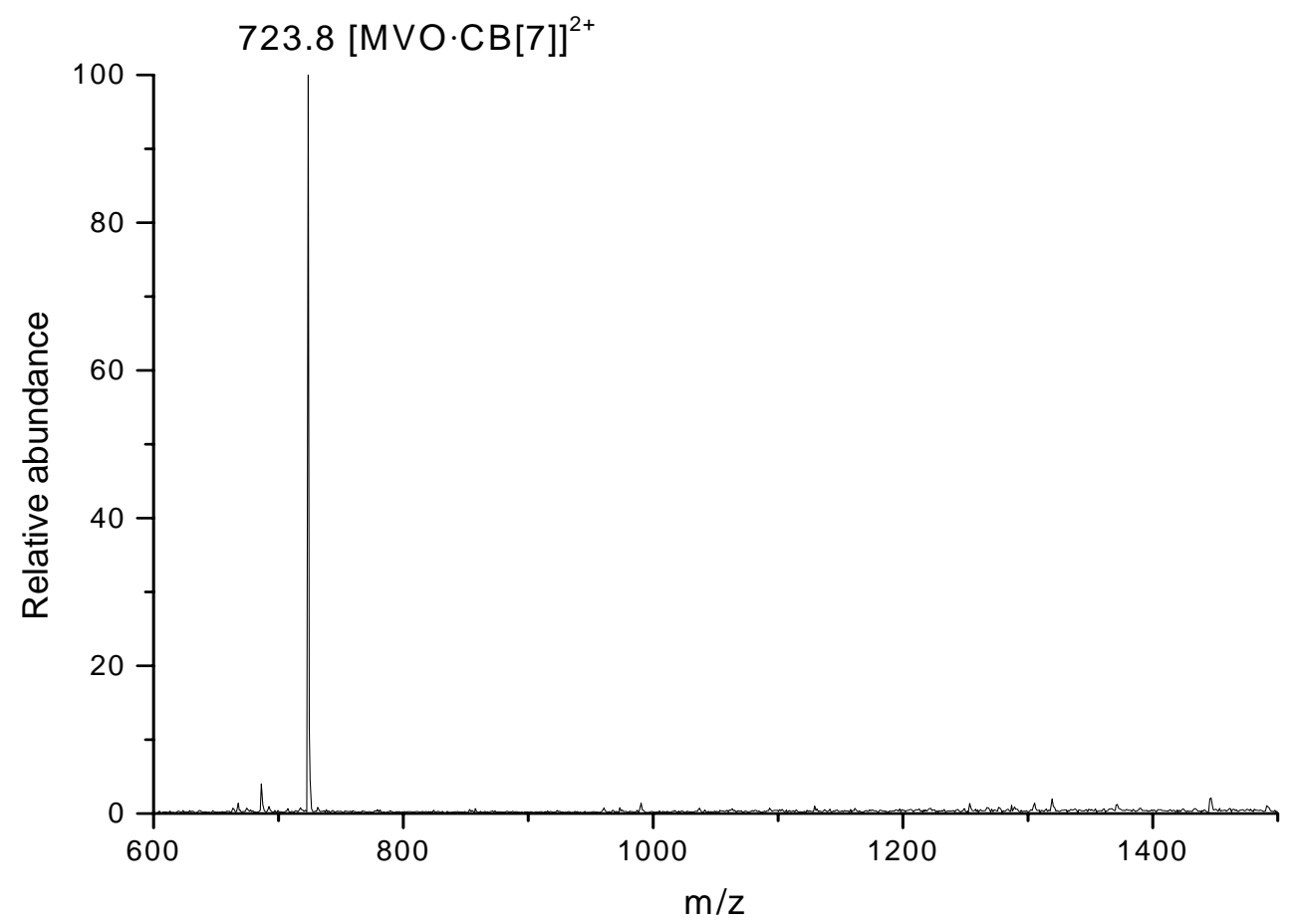

Figure S3. ESI-MS of a solution containing $\mathrm{MVO}^{2+}$ (1 equiv.) and $\mathrm{CB}$ [7] (1.2 equiv.) in water. The peak at 723.8 was assigned to $[\mathrm{MVO} \cdot \mathrm{CB}[7]]^{2+}$. 


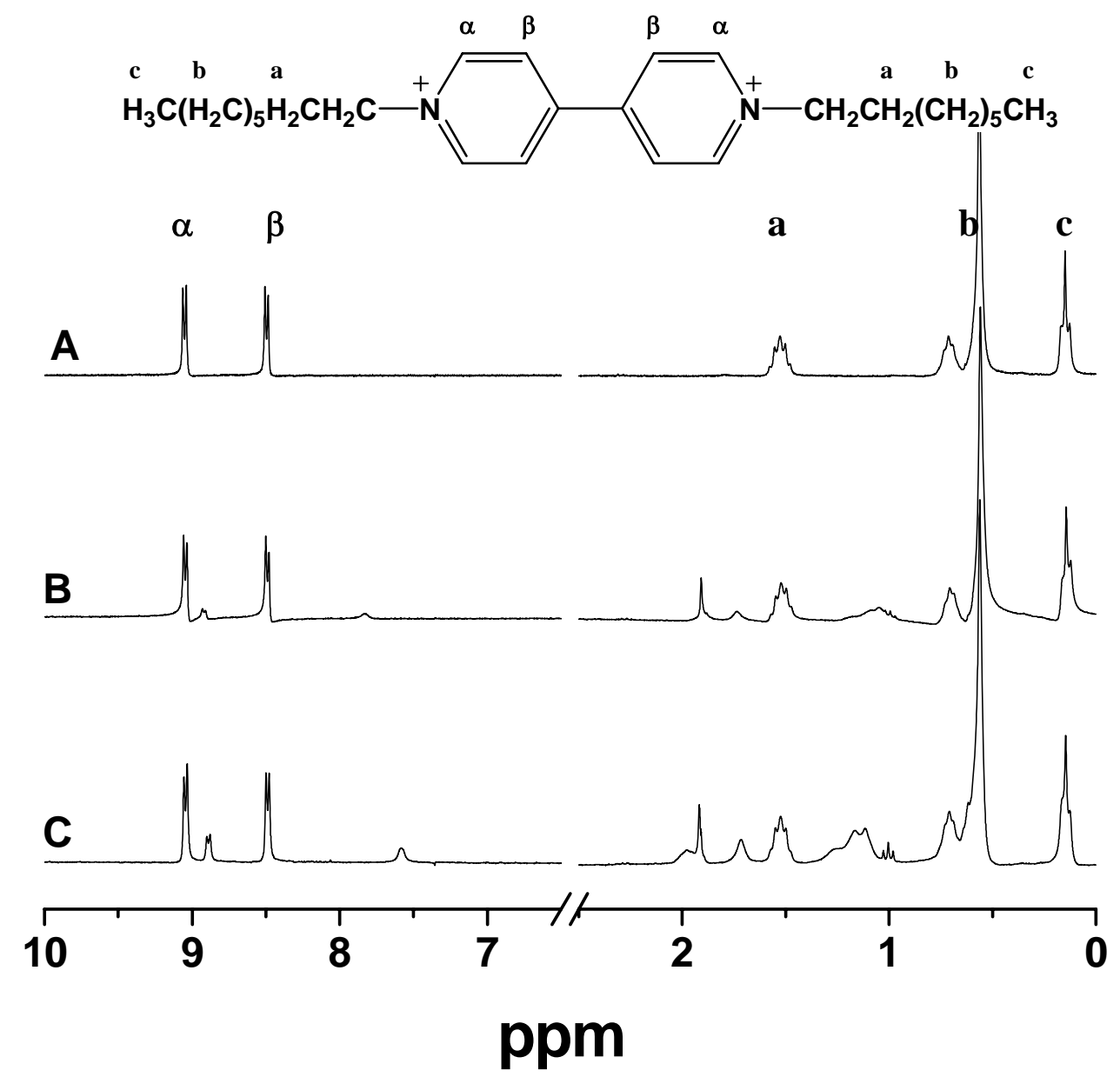

Figure S4. ${ }^{1} \mathrm{H}$ NMR spectra $\left(300 \mathrm{MHz}, 0.2 \mathrm{M} \mathrm{NaCl}-\mathrm{D}_{2} \mathrm{O}, 298 \mathrm{~K}\right)$ of $(\mathrm{A}) \mathrm{OV}^{2+}+2.4$ equiv. $\mathrm{CB}[7]$, (B) $\mathrm{OV}^{2+}+2.4$ equiv. $\mathrm{CB}[7]+4.0$ equiv. $\alpha-\mathrm{CD}$, (D) $\mathrm{OV}^{2+}+2.4$ equiv. $\mathrm{CB}[7]+8.0$ equiv. $\alpha-\mathrm{CD}$. 


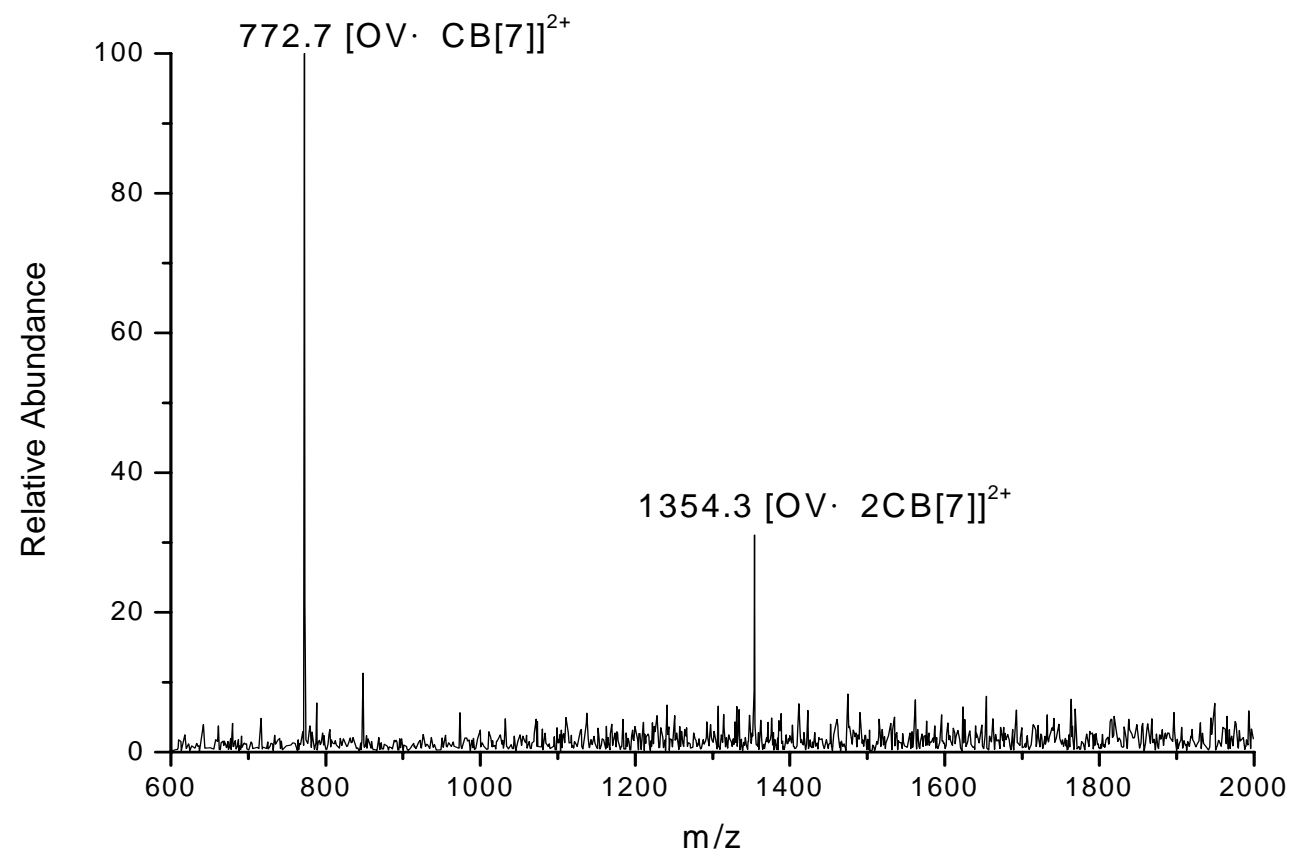

Figure S5. ESI-MS of a solution containing $\mathrm{OV}^{2+}$ (1 equiv.) and $\mathrm{CB}[7]$ (2.4 equiv.) in water. The peaks at 772.7 and $1,354.3$ were assigned to $[\mathrm{OV} \cdot \mathrm{CB}[7]]^{2+}$ and $[\mathrm{OV} \cdot 2 \mathrm{CB}[7]]^{2+}$ respectively. 


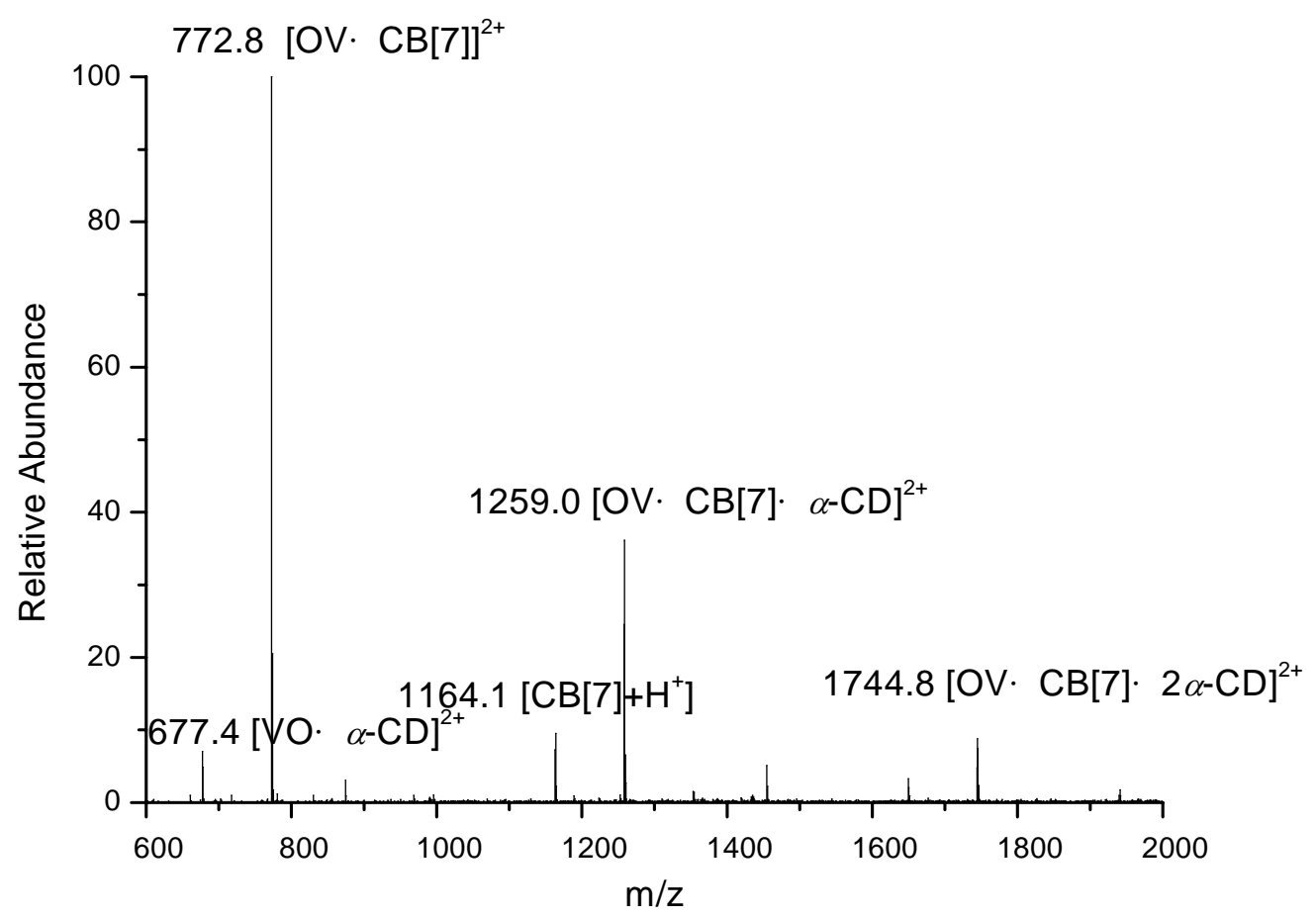

Figure S6. ESI-MS of a solution containing $\mathrm{OV}^{2+}$ (1 equiv.), $\mathrm{CB}[7]$ (2.4 equiv.) and $\alpha-C D$ (5.0 equiv.) in water. The peaks at $677.4,772.8,1,164.1,1,259.0$, and 1,744.8 were assigned to $[\mathrm{OV} \cdot \alpha-\mathrm{CD}]^{2+},[\mathrm{OV} \cdot \mathrm{CB}[7]]^{2+},[\mathrm{CB}[7] \cdot \mathrm{H}]^{+},[\mathrm{OV} \cdot \mathrm{CB}[7] \cdot \alpha-\mathrm{CD}]^{2+}$, and $[\mathrm{OV} \cdot \mathrm{CB}[7] \cdot 2 \alpha-\mathrm{CD}]^{2+}$ respectively. 

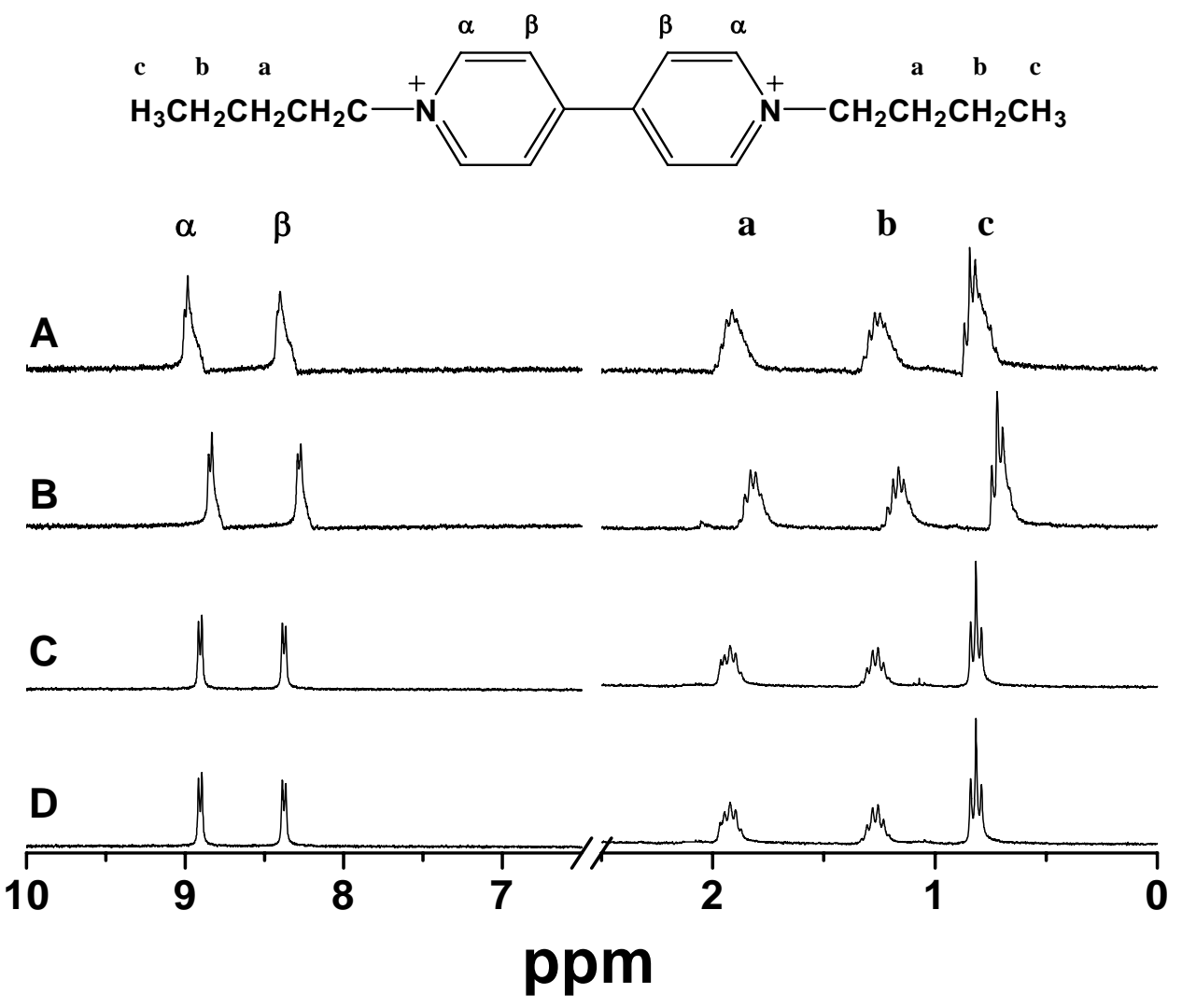

Figure S7. ${ }^{1} \mathrm{H}$ NMR spectra $\left(300 \mathrm{MHz}, \mathrm{D}_{2} \mathrm{O}, 298 \mathrm{~K}\right)$ of $(\mathrm{A}) \mathrm{BV}^{2+}$, (B) $\mathrm{BV}^{2+}+1.0$ equiv. $\mathrm{CB}$ [7], (C) $\mathrm{BV}^{2+}+1.0$ equiv. $\mathrm{CB}[7]+10.0$ equiv. $\alpha-\mathrm{CD}$ and $(\mathrm{D}) \mathrm{BV}^{2+}+10.0$ equiv. $\alpha-C D$. 


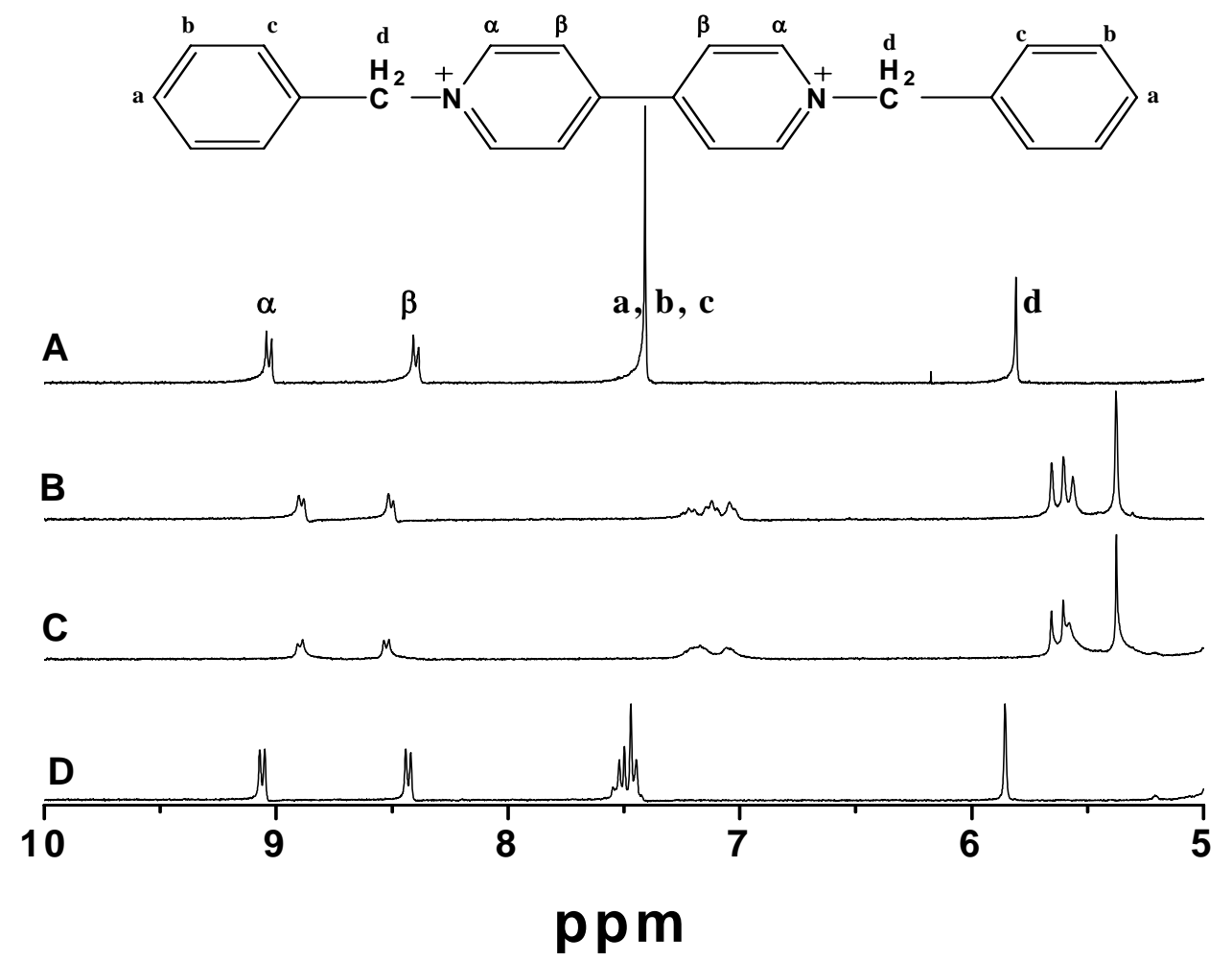

Figure S8. ${ }^{1} \mathrm{H}$ NMR spectra $\left(300 \mathrm{MHz}, \mathrm{D}_{2} \mathrm{O}, 298 \mathrm{~K}\right)$ of $\mathrm{BnV}^{2+}$, (B) $\mathrm{BnV}^{2+}+1.0$ equiv. $\mathrm{CB}[7],(\mathrm{C}) \mathrm{BnV}^{2+}+1.0$ equiv. $\mathrm{CB}[7]+10.0$ equiv. $\alpha-\mathrm{CD}$ and $(\mathrm{D}) \mathrm{BnV}^{2+}+10.0$ equiv. $\alpha-C D$. 


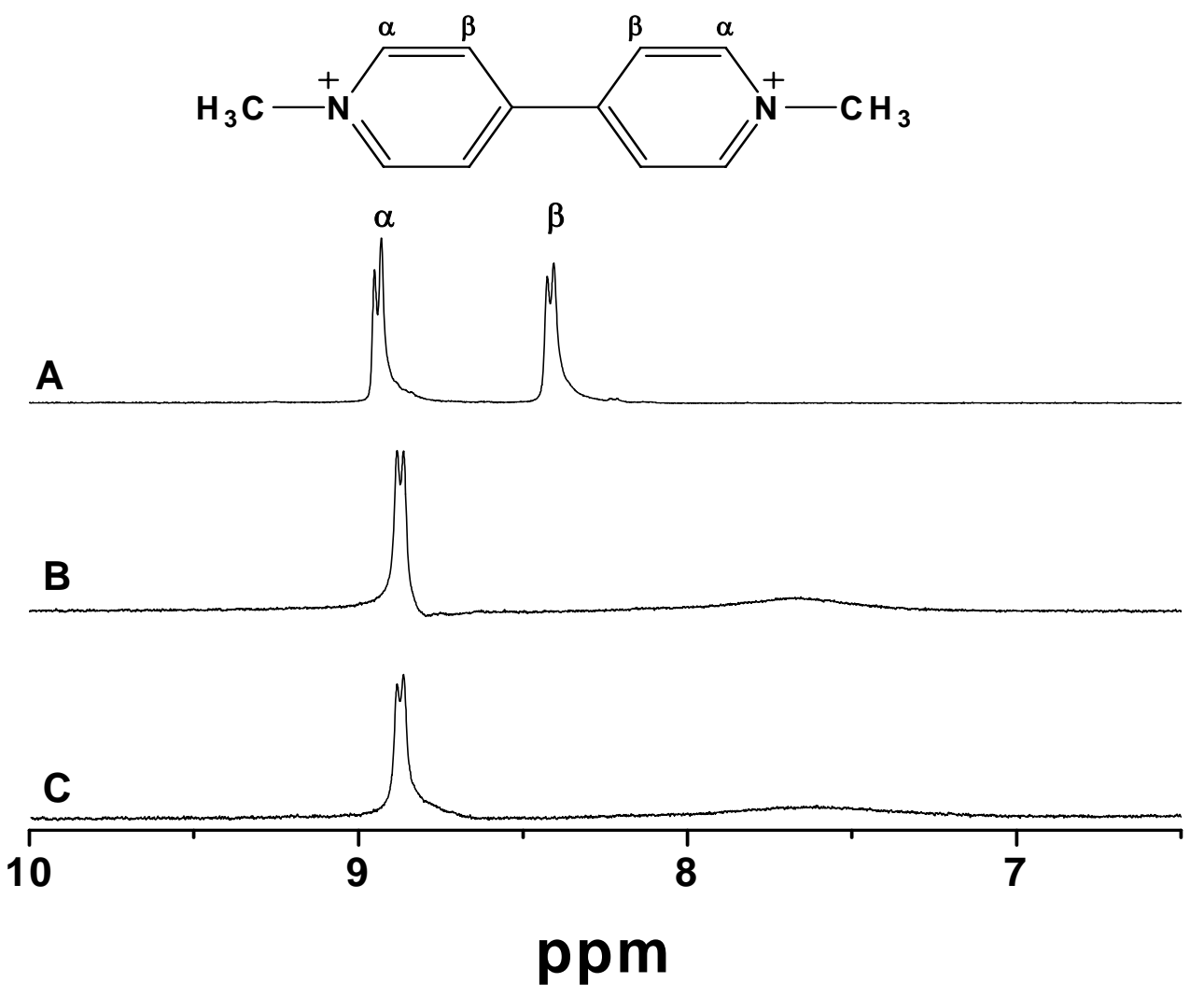

Figure S9. ${ }^{1} \mathrm{H}$ NMR spectra $\left(300 \mathrm{MHz}, \mathrm{D}_{2} \mathrm{O}, 298 \mathrm{~K}\right)$ of $(\mathrm{A}) \mathrm{MV}^{2+}$, (B) $\mathrm{MV}^{2+}+1.0$ equiv. $\mathrm{CB}[7]$ and $(\mathrm{C}) \mathrm{MV}^{2+}+10.0$ equiv. $\alpha-\mathrm{CD}$. 


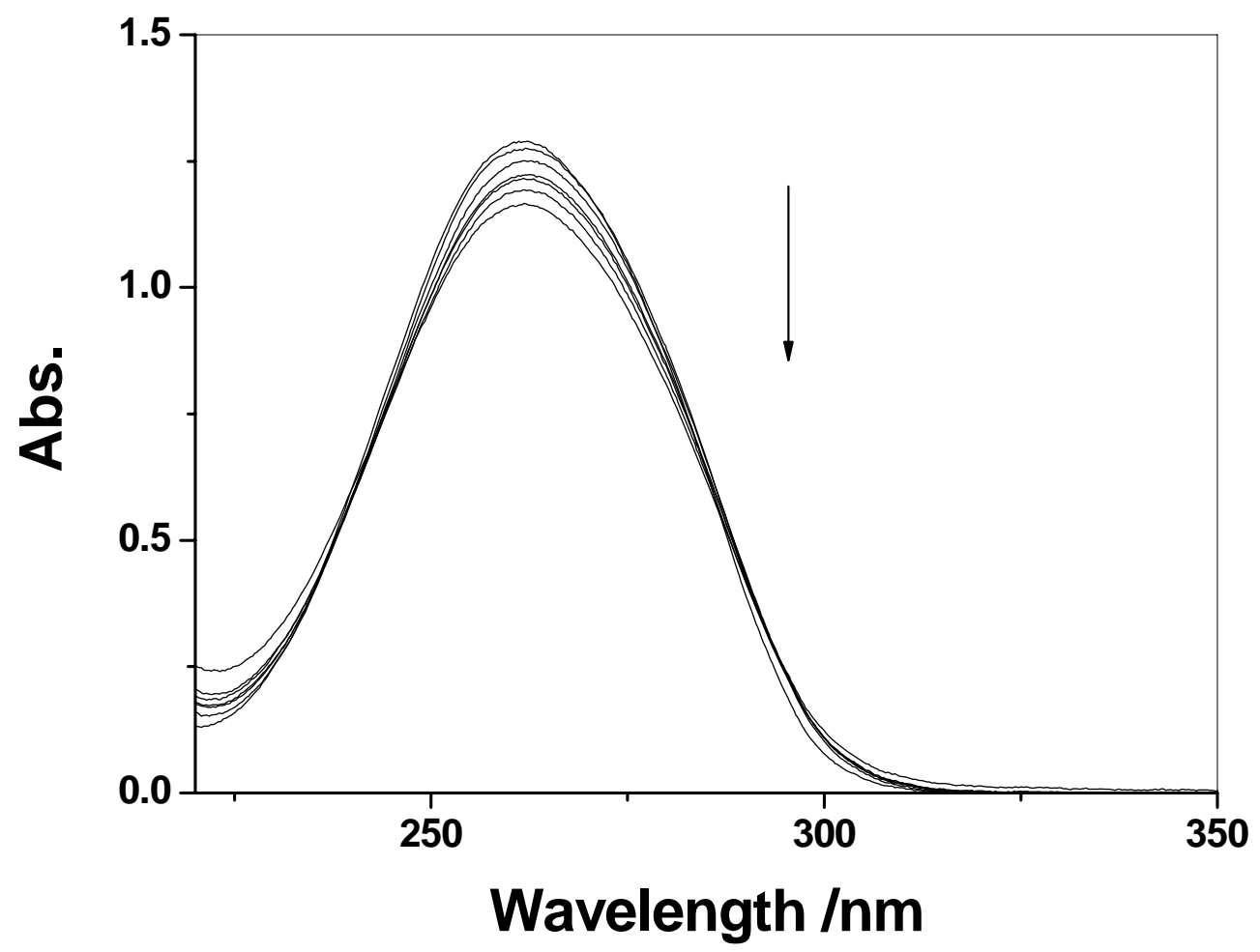

Figure S10. UV-Vis spectra of $50.0 \mu \mathrm{M}[\mathrm{OV} \cdot \mathrm{CB}[7]]^{2+}$ in the presence of increasing concentrations $(0-20.0 \mathrm{mM}$, in the direction of the arrow) of $\alpha-\mathrm{CD}$ in Tris buffer $(\mathrm{pH}$ 7.4) at $298 \mathrm{~K}$. 


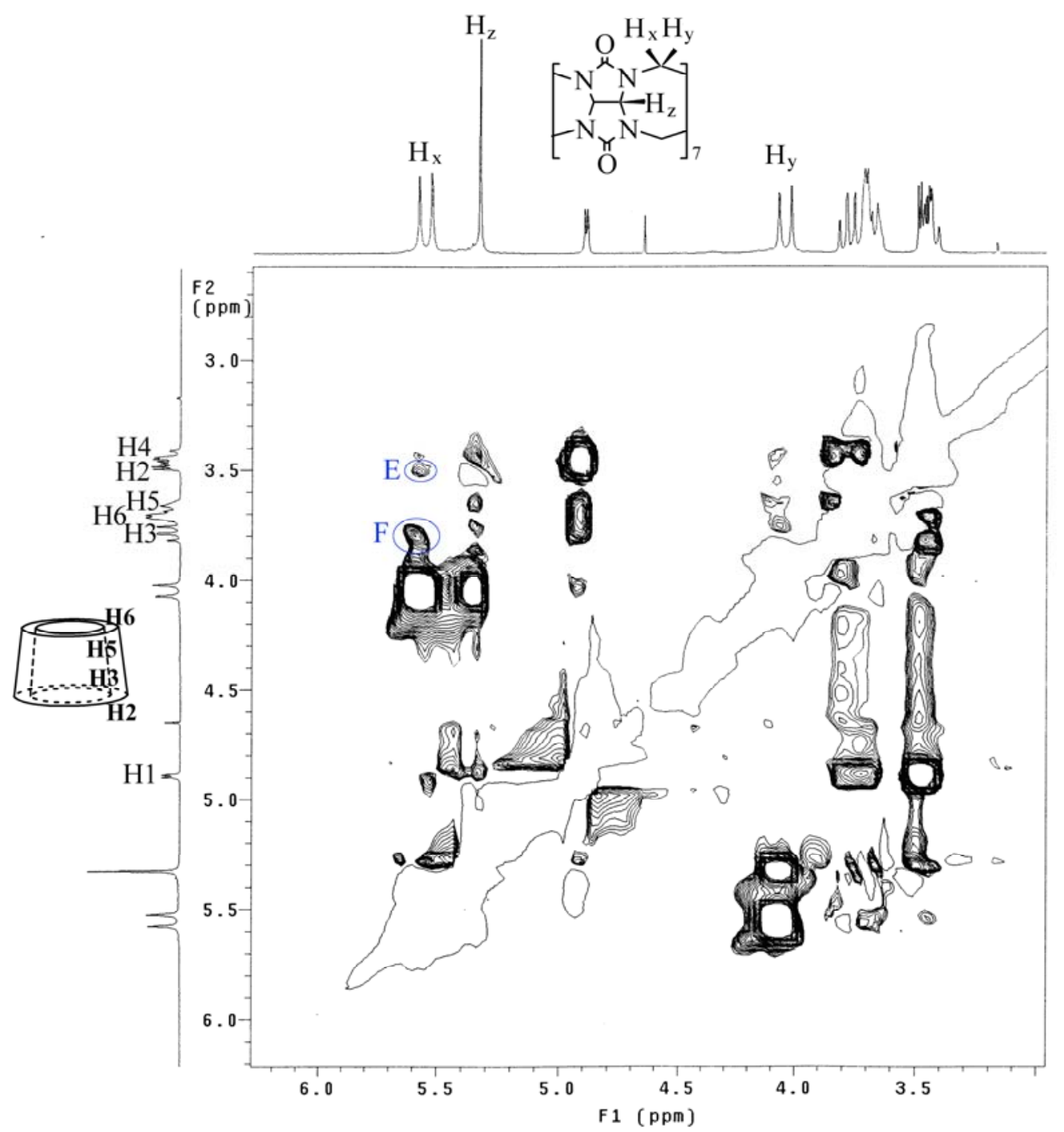

Figure S11. Partial ${ }^{1} \mathrm{H}$ ROESY spectra of a mixture of $\mathrm{MVO}^{2+}(5 \mathrm{mmol} / \mathrm{L}), \mathrm{CB}[7]$ (5 $\mathrm{mmol} / \mathrm{L})$ and $\alpha-\mathrm{CD}(6 \mathrm{mmol} / \mathrm{L})$ in $\mathrm{D}_{2} \mathrm{O}$ at $298 \mathrm{~K}$ with a mixing time of $250 \mathrm{~ms}$. Peaks $E$ and $F$ respectively present the NOE effects of the $\mathrm{H}_{\mathrm{x}}$ protons of $\mathrm{CB}[7]$ with the $\mathrm{H} 2$ and $\mathrm{H} 3$ of $\alpha-\mathrm{CD}$. 


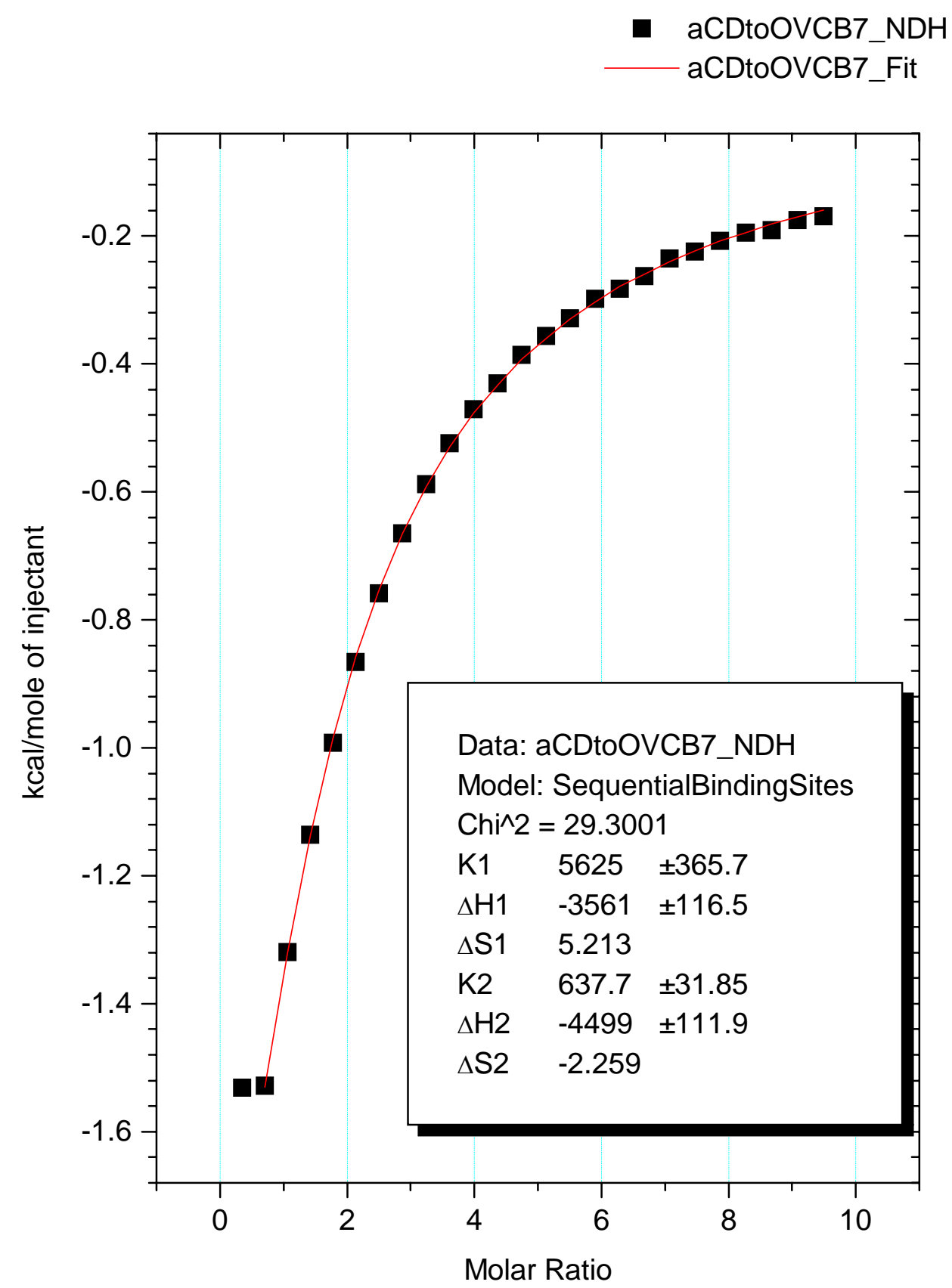

Figure S12. Computer simulation of ITC titration curve using the " $1: 2$ sequential binding sites" model in the case of complexation of $\alpha-\mathrm{CD}$ toward $[\mathrm{OV} \cdot \mathrm{CB}[7]]^{2+}$. 